\title{
Mental Health Seeking Behaviour of Women University Students: An Intersectional Analysis
}

\author{
Original Research \\ Rodrick Lal ${ }^{1}$, Geoffrey Reaume ${ }^{1}$, Christo El Morr ${ }^{2}$, Nazilla Khanlou ${ }^{1}$ \\ ${ }^{1}$ Faculty of Health, York University, Toronto, Ontario Canada; ${ }^{2}$ School of Health Policy, York University, Toronto, \\ Ontario Canada \\ Corresponding author: R. Lal (rodrickl@yorku.ca)
}

\begin{abstract}
This research study explored the mental health help seeking behaviour of racialized and non-racialized women students at a large size public university located in Ontario, Canada. A sample consisting of 491 students participated in the cross-sectional survey. The majority $(n=413,84.1 \%)$ were identified as Canadian racialized women students. The remainder ( $n=78,15.9 \%$ ) were Canadian non-racialized women students. We contend that intersectionality, an emergent theoretical and methodological public health framework, provides a powerful tool for understanding the complex interlocking experiences of gender and racialization in the context of mental health. High levels of depression and anxiety symptoms were reported by both the racialized and non-racialized women students. The proportion of students with CES-D scores > 16 (indicating that may suffer from depression) was higher among the racialized women students $(n=265,64.2 \%$ ) than the non-racialized women students ( $n=39,50.0 \%)$. Approximately, half of the racialized students $(n=202,48.9 \%$ ) had BAS scores $>10$ indicating that they may suffer from anxiety. About half $(n=38,48.7 \%$ ) of the non-racialized students also had BAS scores $>10$ indicating that they may suffer from anxiety.
\end{abstract}

\section{KEYWORDS}

Age, Gender Roles, Racialization, Racism, Stigmas, Student's Mental Health

\section{BACKGROUND}

There are multiple social and structural issues that create mental health problems, such as anxiety, depression and stress in a student's life when engaging in the university environment. University life is often filled with excitement and new experiences for students. It is also the time of life when a developmental transition from youth to adulthood occurs, which some students experience as a sense of loss when separating from communities, family and friends. A substantial volume of research has demonstrated that gender constructed disparities contribute meaningfully to the greater prevalence of depression and anxiety among young women when compared to young men, (Canadian Institute of Health Research, 2016; Iwamoto, Lui \& McCoy, 2011; American Psychiatric Association, 2009; World Health Organization (WHO), 2018). For instance, the lower self esteem of young women in comparison to young men in similar age groups, and their anxiety over their body-image has established an elevated prevalence of depression and of eating disorders in young women in comparison to young men, (Canadian Institute of Health Research, 2016; Iwamoto, et al, 2011; American Psychiatric Association, 2009; WHO, 2020). Saliently, the sentiment of a lack of power and control over one's life especially in racialized women correlates towards with depression. Socially determined gender norms, roles and responsibilities places both racialized and non-racialized women, far more frequently than men, in situations where they have little control over important decisions concerning their lives (Iwamoto, Lui, \& McCoy, 2011; American Psychiatric Association, 2009; WHO, 2018).

The mental health impact of these inequities may be greater on immigrant and second-generation racialized students due to the discrimination and racism they experience (Arday, 2002). University is an environment in which mental health problems 
(Costello, Foley, \& Angold, 2006), including depression, suicide, and substance abuse, combined with stress related to academic performance are likely to occur. Some of the factors that contribute to mental health problems in universities intersects with: structural problems of confronting racism against racialized students; structural violence and public stigma; inadequate university counselling staff and limited hours of operation; the social determinants of living conditions; financial issues; food scarcity; personal career decision-making; developing independence; alcohol misuse; and personal academic demands (Costello, Foley, \& Angold, 2006; Watson, \& Bar 2006; Carpenter-Song, 2010; Corrigan, Watson, \& Barr, 2006). Among those who experience mental health problems, research illustrates that students from racialized backgrounds are unlikely to seek help either from university counselling centres or mental health resources (Carpenter-Song, 2010; Corrigan, et al., 2006).

The hindrance of depression, anxiety and stress are further exacerbated by the demands to acculturate to the dominant Canadian society for many racialized women students, particularly for recent immigrants. Both in the dominant non-racialized Canadian society and in many racialized communities, different cultural values and understandings of emotional independence and women's roles may lead these students to experience additional difficulties as they try to navigate the transition to life at university (Harper, \& Harris, 2010). Few studies have fully explored the intersections of gender, socio-economic status, racialization and racism, ethnicity, professional behaviour and age as they interconnect to influence the experiences of racialized and nonracialized populations of women. Racialized identities are identified as those groups of people that have been socially and politically created as "racially" distinct. In addition, "they have prominent cultural elements, but they are mostly a manifestation of unequal power between groups" (Baum, 2002, P. 11). Consequently, racialized identities are historically and contextually specific differentiated by malleability, flexibility and situationally (Baum, 2002; Arday, 2002; Galabuzi, 2018). More importantly, racialized identities are shaped by power relations (Crenshaw, 1989a, 1991b, 2017c; Davis, 1981; Khanlou, 2010b). In contrast, European settler societies/immigrants are positioned as non-racialized settler societies.
In this paper, we present data from on online survey of Canadian university students with a focus on the intersections of female gender, racialization and mental health help-seeking behaviour. In the survey we asked students questions related to their help seeking behaviour, experiences of accessing help, stigma and issues related to race and acculturation. We argue that intersectionality, an emergent theoretical and methodological public health framework, provides a powerful tool for understanding these complex interlocking experiences in the context of mental health (Morrow \& Halinka-Malcoe, 2017; Rossiter \& Morrow, 2011; Gorman, 2013; Tam, 2013; Cole, 2009). Conceivably, one of the largest disparities in the literature are studies that address the intersections between gender, racialization, stigma and student help seeking behaviour for mental health supports.

Intersecting Factors Influencing Women's Mental Health Help Seeking Behaviour of Racialized and Non-Racialized Students

There are numerous factors that act as barriers contributing to the under-utilization of mental health supports among women, especially racialized women students. At the structural level systemic racism is the overarching barrier, which then plays out at the community, institutional and personal level (Morrow, et al., 2017). Further, racism and acculturation, expertise of professionals, stigma, race-related stress, gender roles, age, cultural and religious beliefs also play a role in help-seeking for racialized women students. For non-racialized students' gender and age may act as significant barriers to help-seeking behaviour.

\section{Gender, Race \& Culture}

Racialized women comprise a large, heterogeneous group, varying by language, geographic location and their post-migration experiences. However, among these groups, family needs and traditions are often considered more important than personal needs; when a woman puts her personal needs ahead of those of her family, her behaviour may be considered selfish and "westernized" (Das, \& Kemp, 1997; Chan, 2013). The different, yet valued structure of family and women's roles in racialized cultures, is important to understand; many women strive to maintain these values after migration (Das et al., 1997; Chan, 2013). 
As a result, racialized women are at the intersection of multiple stigmas with respect to helpseeking behaviour. Not only are their mental health issues closely connected with the cultural stigma of inadequate womanhood or motherhood, but they also generally decline to seek help from either formal or informal sources (Komiya, Good, \& Sherrod, 2000; Chowdhury, Sanyal, Bhattacharya, Dutta, Banerjee, \& Weiss, 2001; Ting, \& Hwang, 2009; \& Paniaguan, 2013). As a result, help-seeking behaviour is mediated by both racialization and gender. This combination can prevent both racialized and non racialized women from seeking help for mental health problems and lead to under-utilization of services. For racialized students, family care and support from religious beliefs are perceived as more important than professional mental help to maintain mental wellbeing (Chan, \& Hayashi, 2010; Chong, Verma, Vaingankar, Chan, Wong, \& Heng, 2007; Chowdhury, et al., 2001).

\section{Age}

Several scholars (Rickwood, Deane, Wilson, \& Ciarrochi, 2005), found in younger women age disparities in help-seeking behaviour for mental health concerns, especially in young people between the ages of (18-25). Women in the age range between (18-25), are at the highest risk of having mental health issues and yet had low help-seeking rates (Rickwood, Deane, \& Wilson, 2007). This suggests a negative link between age and help-seeking behaviour for mental health issues informed by different attitudes towards mental health.

Furthermore, for young adults in the age range of (18-25), the fear of breaches of confidentiality and lack of trust may relate to the fear of public stigma (Rickwood, et al, 2007). This may create embarrassment, shame and loss of face in front of peers and friends (Barker et al., 2005). Evidence confirms that positive past experiences, social support and encouragement from family members, and family doctors are often the preferred sources of help over mental health professionals for this age group (Rickwood, et al, 2007; Zachrisson, Rodje, \& Mykletun, 2006).

\section{Systemic Racism}

Institutionalized racism is defined as, "differential access to the goods, services, and opportunities of society by race" (Jones, 2000, p. 1212). Institutionalized racism becomes structural when it is normalized and codified into institutions. Jones (2000), developed a framework for understanding racism at three levels: institutionalized, personally mediated, and internalized. The barriers related to systemic racism explored below are the most relevant to the current study and also those most often discussed in the literature (Gary, Yarandi \& Scruggs, 2003; Gary, 2005; Paradies et al., 2015; Sam \& Barry, 2010; Hwang, \& Ting, 2008; Mikolajczyk, Bredehorst, Kheilalfat, Maler, \& Maxwell, 2007; Potochnick \& Perreira, 2010).

\section{i) Racism and Acculturation}

Acculturation encompasses how people adjust to a new culture, language and environment and has been linked to health and mental health problems due to structural racism (Berry, 2008a; Khanlou, Koh, \& Mill, 2008). Balls Organista, Marin, \& Chun, (2010, p. 105), define acculturation stress as, "a dynamic and multidimensional process of adaptation that occurs when distinct cultures come into sustained contact." People experience different degrees and instances of integration with the mainstream culture and maintenance with the heritage culture contingent upon individual, group, and environmental factors.

For university-aged, racialized students, researchers have noted additional difficulties (Sam, et al., 2010; Hwang, et al., 2008; Mikolajczyk, et al., 2007). These difficulties vary depending on whether the racialized student is Canadian-born or a recent immigrant. For Canadian-born racialized students, the issues include intergenerational family conflict and handling discrimination associated with racialized status (Khanlou, 2003a). Whereas racialized immigrants often experience and face: identity confusion; struggle adapting to a different educational and political system; and adjusting to new social norms and coping with feelings of isolation and disconnection (Potochnick \& Perreira, 2010; Javier, Lahlff, Ferrer, \& Huffman, 2010).

\section{ii) Stigma and Racism-related Stress}

Mental health stigma intersects with experiences of racialization and culture. A distinction exists between stigma by virtue of being for a racialized 
group and stigma from having mental health issues; both create a barrier to racialized students from seeking help. Once women, especially racialized women have been stigmatized through mental illness labels, the foundation has been established for them to feel devalued and excluded from mainstream society. The stigma of receiving a psychiatric "label" may act as a stressor, impairing psychiatric symptoms or impeding recovery (Ting \& Hwang, 2010). Evidence suggests that high levels of stigma associated with negative attitudes predict low use of mental health services for racialized groups. Several surveys have revealed that people with significantly high levels of self-stigma are less likely to seek professional services than those with significantly low levels of self-stigma (Vogel et al., 2006).

\section{iii) Expertise of Professionals}

Racist beliefs and stereotyping in the mental health professions (i.e., counsellors, psychology, psychiatry) are regularly assumed to be persuasive determining factors in intake, assessment and diagnosis and misdiagnosis of mental health concerns. (Bui, \& Takeuchi, 1992). Unfortunately, because of these problematic briers racialized groups are frequently misdiagnosed with mental health problems (Bui, et al., 1992).

In summary the construct of health and mental health is not merely the result of biological factors but is also influenced by social and structural factors. Unlike biomedical and socio-psychological models/theories, intersectionality advocates racialized groups confront (structural) barriers within the broader political, economic, historical, and social systems due to existing intersecting structural inequalities in Canadian society. Further (Javier, et., 2010; Iwamoto, et al., 2011) emphasize that the internal variations within communities based on female gender, class, age, ability, and sexuality are salient determinants of healthcare and could deter racialized groups in help-seeking. These researchers' correlate the healthcare behaviour of people especially racialized groups as a power relation comprised of multifaceted intersectional power relations and inequitable social relationships.

\section{METHODS}

The concept of intersectionality was formulated by Kimberlé Crenshaw in the context of legal studies and the development of critical race theory (Crenshaw, 1989a; 1991b; 2017c). However, the concepts underlying intersectionality have a long activist and intellectual history. Intersectionality has its roots in the activism and scholarship of Afro-American and Indigenous feminists in the US and the global South (Davis, 1981; Mohanty, Russo \& Torries, 1991; Donadey, 2002; Morrow, Halinka-Malcoe, 2017). Intersectionality is increasingly being adopted as analytic tool for research and activism. Hill, \& Bilge, (2016) describe intersectionality as:

When it comes to social inequality, people's lives and the organization of power in a given society are better understood as being shaped not by a single axis of social division, be it race or gender or class, but by many axes that work together and influence each other. Intersectionality as an analytic tool gives people better access to the complexity of the world and of themselves (pg. 2).

Increasingly, intersectionality is being attentive in the context of mental health research (Morrow, et al., 2017; Gorman, 2013; Tam; 2013; Cole, 2009; Rossiter, et al., 2011) and is being acclaimed for its contributions to understanding the complex interactions between social positioning (race, class, ethnicity, gender) and what these interactions tell us about power relations in mental health (Morrow, et al., 2017). While intersectionality is customarily assumed to be principally used in qualitative research (Cole, 2009); it is also increasingly used in quantitative studies (Parent, Hammer, Bradstreet, Schwartz \& Jobe, 2018). Indeed, sizeable group figures are distinctively suited to quantitative intersectional surveys which allows for analysis of identities and individual diversities features (Parent, et al., 2018; Scott, \& Siltanen, 2017). In this quantitative study, intersections were captured in the data through relationships amid groups (Cole, 2009).

\section{Sample of the Student Population}

The target population for this study was specifically racialized women, and non-racialized women students enrolled at a large size public university located in Ontario, Canada. While the focus in this study was on racialized women students, all students were invited to participate to compare and contrast for deeper understanding. Participations were not restricted by any other demographic variable, such as age, gender-sex, marital status, socio-economic 
status, education level, ethnic background, disability or history of mental illness.

Participants were recruited through presentations at university classes in various faculties and departments. To increase the response rate, the researcher attended several classes where, with the collaboration of the professor, the students completed the surveys in class. Participants who clicked the link were led externally to Survey Monkey, an electronic survey website, to complete their responses to the instruments. Ethics approval was granted by the University Ethics Board.

\section{Socio-Demographic Survey}

The Socio-Demographic survey elicited information about the socio-demographic characteristics of the students, including gender-sex, age, relationship status, citizenship, racial/ethnic identity, student status, living situation, use of University counselling services, use of online mental health/app information system, and previous diagnosis.

The data analysis was conducted utilizing SPSS vs. 24.0 and the methods described by Field (2013). Table 1 lists the definitions of the variables used to test the research questions. It also lists the continuous (interval level) variables measured with Likert-Scales, coded in SPSS using variable names with four letters. The socio-demographic and contextual characteristics of the respondents were summarized by frequency distributions (counts and percentages of each category). The continuous (interval level) variables were summarized using descriptive statistics (minimum, maximum, mean, median, and standard deviation). The mean scores $\pm 95 \%$ confidence intervals $(\mathrm{Cl})$ of the ten variables were computed to compare the mean scores between different groups of students. A statistically significant difference $(p<.05)$ between two mean scores was inferred if their $95 \% \mathrm{Cl}$ did not overlap (Fidler \& Loftus, 2009; Knezevic, 2008).

\section{RESULTS}

Descriptive Analysis: The Intersectionality of Racialized and Non-Racialized Women Student's Mental Health Seeking Behaviour
The socio-demographic characteristics of 491 respondents (counts and percentages in each category) classified by racial/ethnic group ( $n=78$, $15.9 \%$ non-Racialized; $n=413,84.1 \%$ Racialized). The division between non-racialized and racialized women students used in this study encompassed a very wide range of ethnic/racial diversity. This wide diversity is represented in Figure 1 by a pie diagram which illustrates the racial/ethnic diversity of the sample $(\mathrm{N}=491)$. A total of 570 students participated in the research, 79 male student's data were deleted from the research.

The women students ranged widely in age from 18 to 65 years. The predominant age groups were 18 to 20 years, and 21 to 30 years, collectively representing $82.9 \%$ of the non-racialized women students, and $92.3 \%$ of the racialized women students. The proportion of Canadian citizens by birth was higher in the non-racialized students (82.1\%) compared to the racialized students (59.3\%).

\section{The multiple regression analysis}

From the multiple regression analysis (Table 2) high levels of depression and anxiety symptoms were reported by both the racialized and non-racialized women students. The proportion of students with CES-D scores $>16$ (indicating that they may suffer from depression) was higher among the racialized students ( $n=265,64.2 \%$ ) than the non-racialized students $(n=39,50.0 \%)$. About half of the racialized students ( $\mathrm{n}=202,48.9 \%$ ) had BAS scores $>10$ indicating that they may suffer from anxiety. About half ( $n=38,48.7 \%$ ) of the non-racialized students also had BAS scores $>10$ indicating that they may suffer from anxiety.

The multiple regression analysis utilized to predict Stigma had strong practical significance $(R 2=.070)$. Identification with Heritage Culture, Gender and/or sex, and Race Related Stress were significant predictors of Stigma among the racialized women students. When Identification with Heritage Culture increased by 1 , the Stigma score increased $(\beta=.216)$.

Further, the regression statistics supported the question that Identification with Mainstream Culture, Ethnic Identity, and Race Related Stress were not significant predictors of depression, anxiety, stigmatization, attitudes toward seeking help, or intention to seek help among the non-racialized 
women students. Thus, the mean score for Attitudes Toward Seeking Help was significantly higher among the non- racialized women students $(M=28.56)$ than the racialized women students ( $M=26.63$ ). Saliently, the mean score for Race Related Stress was significantly higher among the racialized women students $(M=5.95)$ than among the non-racialized women students $(M=2.61)$.

\section{DISCUSSION}

This research examined the factors associated with the attitudes and beliefs concerning racialized and non-racialized women students' mental health helpseeking behaviour. The study focused on racialized women university students because insufficient research has been undertaken in a large size public university in the province of Ontario Canada, to highlight the concerns of racialized students who do not seek mental health services.

Help-seeking behaviours are very complex for racialized women students who experience multiple forms of discrimination based on gender/sex, income, immigration status, stigma, race, ethnicity, class, living situation and age. The results of the descriptive data analysis revealed that the proportions of students with CES-D scores $>16$ (indicating that they suffered from clinical depression), was higher racialized women compared to the non-racialized women. The regression analysis indicated that identification with heritage culture and race related stress were statistically significant predictors of depression symptoms among the racialized women students. However, for the non-racialized women students, mainstream acculturation, ethnic identity, and race-related stressors were not statistically significant predictors of depression due to their social and cultural privileges belonging to the dominant non-racialized Canadian society.

These findings are consistent with other surveys concluding that racialized women students are significantly more likely to report depressive symptoms than non-racialized students (Morgan et al, 2006; Walsemann, et al., 2011). The empirical evidence indicates that depression is correlated with many other variables of interest to this study, including stigmatization related to mental health (Link et al., 2001; Corrigan, 2007). The reasons for the high incidence of depression among racialized women students may include racism process stigmatization associated with acculturation (Link et al., 2001; Walsemann, et al., 2011); experience of racial discrimination (Borges et al., 2011; Joseph, 2015); and gender role conflict (Good \& Wood, 1995).

The descriptive analysis revealed that the mean scores for "Attitudes Toward Seeking Help," "Intention to Seek Help," "Identification with Mainstream Culture," and "Race Related Stress" were meaningfully lower in the racialized women students than in the non-racialized women students. Furthermore, the mean score for "Stigma" was significantly higher in the racialized women students than in the non-racialized women students. Regression analysis indicated that a high level of stigma was a significant predictor of lower attitudes towards help seeking and lower intentions towards seeking mental health counseling amongst racialized women students. Similarly, Rao, Feinglass, and Corrigan (2007), found that racialized students at a community college in USA exhibited greater stigma than non-racialized students. These findings are consistent with several previous studies concluding that stigmatization related to mental health is an important predisposing characteristic acting as a barrier to the use of mental health services by racialized students (Gary, 2005; Gary et al., 2003; Ting \& Hwang, 2010; Walsemann, et al., 2011).

Further, this study correlated the intersection between gender and race plays an important role in help seeking behaviour. Mental health actions are socially structured behaviours, practiced in the same way as other social and cultural activities (Courtenay, 2000a). As a result, the "doing of health" is the doing of femininity gender/sex role stereotype fulfilment (Courtenay, 2000a). The "doing" of help-seeking is consistent with the norms of traditional femininity and thus reflect the gender/sex role stereotypes of a given time and place (Courtenay, 2000a). While racialized women also seek help less frequently than non-racialized women, they seek mental help more frequently than racialized men (American Psychiatric Association, 2009; Courtenay, 2000a). However, racialized women's students mental help-seeking involved informal supports from friends and family members. These connections are often vital for racialized women because it provides much needed non-professional support and creates bonding among them. This could be emphasized as being a very supportive behaviour from cultural safety perspective. 
Thus, non- racialized women students, the situation is somewhat healthier, since dominant femininity in Canadian society encourages mental help-seeking, but racialized women experience: multiple stigmas, racism, and discomfort with lack of cultural safety with the health care system often prevents help-seeking from professionals. The concept of cultural safety is particularly relevant to mental health professionals as it seeks to promote cultural integrity and the promotion of social justice, equity and respect. It dictates that mental health professionals should be aware of a person's cultural background and the impact of colonialism and racism on mental health and strive to create an environment that is safe and supportive (McGough et al, 2018).

Age evolves to an important variable in mental help-seeking behaviour. The predominant age group of the students at who participated in the survey was 18 to 30 years, collectively representing $82.9 \%$ of the non-racialized women students, and $92.3 \%$ of the racialized women students. The older students (age 26 to 65 years) in the racialized women students tended to have higher scores for "Attitudes Toward Seeking Help" than both racialized and non-racialized women students (age 18 to 25 years). Previous studies have concluded that students in the ages of 18-25 years represent at-risk for all groups due to high risk of mental health issues with associated with low help-seeking rates (Rickwood, et al, 2000a). There may be links between age and help-seeking behavior for mental health issues informed by variants in attitudes towards mental health issues between different cultures and generations.

Research on racialized groups (Paniagua \& Yamada, 2013; Wang, et al, 2007; Rao, et al, 2007) has indicated that family and friends strongly influence help-seeking. As a result, family and friends were also important and influenced participants to engage in mental help-seeking behaviour. In the survey, the mean scores for Attitudes Toward Seeking Help were significantly higher among the students who lived with their family, compared with the students who lived off or on campus. This finding was surprising as we assumed that women students living on campus might be more likely to seek mental help, because of lack of family influence and availability of services.

Partners and friends were the associates from whom both racialized and non-racialized women students were most likely to seek mental help or advice if they were experiencing mental health issues. Mental health professionals, relatives/family members, and doctors/GPs were less likely to be consulted. Professors/academic advisors, phone helplines, ministers or religious leaders, and chat rooms were the least likely sources of help or advice. The University Counselling Centre did not have a significant impact on either non-racialized or racialized women students.

These findings support the suggestion that social support from friends and family members may be important to lay the foundation for mental help seeking behaviour. Several researchers (Vogel et al., 2007; 2001; Gulliver et al., 2010; Gulliver et al., 2012) postulated that most people including racialized and non-racialized women students who engaged in therapy for mental health care are more acceptable when a designate (e.g., parent or partner) advocates for help seeking. Therefore, social support and positive reinforcement appears to be a facilitator of mental help seeking behaviour for women students.

Further, this survey revealed that previous diagnosis was a statistically significant predictor of "Attitudes Toward Seeking Help". This finding is consistent with other studies concluding that previous experiences may increase the potency to influence both non-racialized and racialized students' decision to seek help for mental health issues (Surgenor, 1985; Jorm et al., 1997). Unfortunately, racialized women students seek less help from mental health professionals. This could also be a positive behaviour, given the nature of the deplorable history of how racialized people generally have been mentally misdiagnosed by mental health professionals and mistreated within the mental health system (Jorm et al., 1997). Therefore, it was assumed in this study that social and electronic mediums would be utilized by both groups of students especially racialized students. Regrettably, there was no significant association between the use of the online information system and racialized and non-racialized women students

\section{IMPLICATIONS OF THE RESULTS}

Significant positive correlations were found between Attitudes Toward Seeking Help, Informal Help Seeking, and Intention to Seek Help. These three variables were all negatively correlated with Stigma. 
Moreover, the results of the correlation analysis conducted using the data collected in this survey suggested that what the women students believed other people might think about seeking professional help for mental health issues, associated with stereotypical societal norms and values. (i.e., their level of stigmatization) may reduce the levels of the students' intentions to seek help as well as the levels of their help seeking behaviour. These findings were consistent with several previous studies concluding that stigmatization is an important predisposing characteristic acting as a barrier to the use of health/mental services by racialized university students (Gary, 2005; Gary et al., 2003; Rao et al., 2007; Ting \& Hwang, 2010).

Policy architects in the health and mental health environments have sought to develop explanatory models and theories to understand help-seeking behaviour. This knowledge is meant to assist health professionals, policy makers, researchers, and lay persons in understanding how and when a racialized woman student utilizes health care for physical and mental health needs. A significant amount of research has highlighted the prevalence rates of mental health problems in non-racialized and racialized students. However, utilization of mental health services varies according to power relations based on positionality related to race and ethnicity with research suggesting that racialized women students and racialized population under-utilize mental health services (AbeKim et al., 2002). Further, most of these help seeking theories and models reflect power relationships, western values, the experiences of the dominant nonracialized population, and are based on the principles of individuality. These help-seeking theories lack a structural analysis that considers the intersectionality of mental health.

University administrations, student organizations, faculty, and counselling faculty can develop in-class cultural safety educational programs concerning mental health issues for students. This action can cultivate an environment that may reduce the intersections of stigma, stress, anxiety, and depression, and increase help-seeking behaviour. These courses would use an intersectionality lens and demonstrate a commitment to gender equity to engage students to become ambassadors regarding mental health problems to the wider communities, including their families. Additionally, working in concert in the classroom setting may reduce discrimination and racism between the non-racialized and racialized student groups. Operationalizing these recommendations requires a combination of coherent policy, multi-sectoral solutions with strong leadership by the counselling faculty, and community level action. Action on the social determinants can advance student's physical and mental health resources and provide a culturally safe university environment. The combination of improvements in structural factors, financial resources, daily living conditions, and social determinants can effect emancipation, freedom, and ultimately, mental health and equity.

\section{LIMITATIONS}

There is the possibility of cultural response bias, referring to the peculiar cultural communication styles of many respondents, particularly of racialized women, to provide consistently biased answer patterns to questionnaires concerning health and social issues (Minkov, 2010; Smith, 2004). Some respondents both racialized and non-racialized women students may consistently agree with all of the items (acquiescence response bias), or alternatively, they may consistently answer at the extreme end of each item scale (extremity response bias) irrespective of what they believe is the true answer. Missing values and response bias may, therefore, limit the validity and reliability of the results of this study. Some of the instruments utilized in this research may not be in-link with the values and characteristics of the diverse racialized groups in this study. As a result, it is essential to create an open environment in order to redirect university policies based on equity mental health policies toward designing strategies that will help to improve psychological counseling and other social/religious and healthcare services for racialized and nonracialized women students.

\section{CONCLUSION}

In conclusion, this study uncovered that a high proportion of the racialized and to a lesser extend non-racialized women students in a large size public university in the province of Ontario Canada reported, that they suffered from mental problems including depression, anxiety, and race related stress. The intersectionality of depression, anxiety, stigma, race related stress and stigmatization does hinder mental help-seeking behaviour. A higher level of stigma was 
also a predictor of negative attitudes and lower intentions towards seeking mental health counseling amongst the racialized women students.

Unfortunately, due to structural problems of racism and acculturation, stigma is characteristic among racialized women students. Fortunately, family and friends heightened the foundation for good mental health and help-seeking behaviour for racialized and non- racialized women students. Mental help-seeking behaviour is an important issue to address, in view of the enormous growth of immigrant students and minority groups who become racialized in Canada.

Future quantitative and qualitative research should expand on how the intersections of stigma are significant mediators of the relationship between acculturation and the attitudes of the students towards seeking mental health treatment, and how this relationship is translated into practice. The integration of quantitative and qualitative data across several studies may also help to reveal the complex nature of how gender and race impact mental health help seeking behaviour.

Notwithstanding the limitations of this exploratory research, this is one of the few studies known to address the mental health problems and needs of racialized and non-racialized women student populations in Ontario, Canada. As a result, the practical implications of this study may serve to inform University governance to develop new policies on developing in class programs on mental health and equity. In addition, the administration and faculty need to design cultural/gender safety counselling programs and educate mental healthcare professionals / counsellors to improve their services and address the intersectional needs of racialized students in universities across Canada, and postsecondary institutions worldwide.

\section{REFERENCES}

Abe-Kim, J., Takeuchi, D. T., Hong, S., Zane, N., Sue, S., Spencer, M. S. Alegría, M. (2007). Use of mental health-related services among immigrant and US-born Asian Americans: Results from the national Latino and Asian American study. American Journal of Public Health, 97(1), 91-98.
Adams T., \& Moore, M. (2007). High-risk health and credit behaviour among

18 to 25-year-old college students. Journal of American College Health, 56, 101-108.

Addis, M. E. \& Cohane, G. H. (2005). Social scientific paradigms of masculinity and their implications for research and practice in men's mental health. Journal of Clinical Psychology, 61, 633-647.

Aegisdottir, S., O'Heron, M., P., Hartong, J. M., Haynes, S. A., \& Linville, M. K. (2011). Enhancing attitudes and reducing fears about mental health counseling: An analogue study. Journal of American College Health Association.

American College Health Association, (2016). American College Health AssociationNational College Health Assessment II: Ontario Canada Reference Group Executive Summary Spring. Hanover, MD.

American Psychiatric Association. (2009). Women's mental health issue paper. Retrieved from http://www.psychiatry.org/File\%20Library/ Practice/Diversity/Diversity\%20

Resources/Womens-Mental-Health-Issue.pdf

Arday J. (2002). Fighting the tide: Understanding the difficulties facing Black, Asian and Minority Ethnic (BAME) Doctoral Students' pursuing a career in Academic. Educational Philosophy and Theory: pages 1-8.

Auerbach, R. P. et al (2018). The W.H.O. world mental health surveys international college project: prevalence and distribution of mental disorders. Journal of Abnormal Psychology, 4(13).

Augsberger, A., Yeung, A., Dougher, M., \& Hahm, H. C. (2015). Factors influencing the underutilization of mental health services among Asian American women with a history of depression and suicide. BMC Health Services Research, 15(1), 542.

Balls Organista, P., Marín, G., \& Chun, K.M. (2010). The psychology of ethnic groups in the United States. Thousand Oaks, CA: Sage.

Barney, L. J., Griffiths, K. M., Jorm, A. F., \& Christensen, H. (2006). Stigma about depression and its impact on help-seeking intentions. Australian and New Zealand Journal of Psychiatry, 40, 51-54.

Bathje, G. J., \& Pryor, J. B. (2011). The relationships of public and self-stigma to seeking mental 
health services. Journal of Mental Health Counseling, 33, 161-177.

Baum, F. (2002). The New Public Health (2nd ed.). Melbourne, Oxford University Press.

Berger, J. M., Levant, R. F., McMillan, K. K., Kelleher, W., \& Sellers, A. (2005). Impact of gender role conflict, traditional masculinity ideology, alexithymia, and age on men's attitudes toward psychological helpseeking. Psychology of Men and Masculinity, 6, 73-78.

Berry, J. W. (2005a). Acculturation: Living successfully in two cultures. International Journal of Intercultural Relations, 29(6), 697-712.

Berry, J.W. (2006b). Acculturation: A conceptual overview. In M.H. Bornstein \& L.R. Cote (Eds.), Acculturation and parent-child relationships: Measurement and development. Mahwah: Erlbaum.

Broman, C.L., Mavaddat, R. \& Hsu, S. (2000). The experience and consequences of perceived racial discrimination: A study of African Americans. Journal of Black Psychology, 26, 165-1 80.

Brown, T.N. (2003). CRT speaks to the sociology of mental health: Mental health problems produced by racial stratification. Journal of Health and Social Behaviour, 44, 292-301.

Blanco, C. Okuda M, \& Wright C. (2008). Mental health of college students and their noncollege-attending peers: Results from the national epidemiologic study on alcohol and related conditions. Archives of General Psychiatry, 65(12), 1429-1437.

Borges, G., Azrael, D, Almeida, J., Johnson, Renee, M., Molnar, B. E., Hemenway, D., \& Miller, M. (2011). Immigration, suicidal ideation and deliberate self-injury in the Boston youth survey 2006. Suicide \& Life - Threatening Behaviour, 41, 193-202.

Bowleg, L. (2008) When Black + Lesbian + Woman =/ Black Lesbian Woman: The methodological challenges of qualitative and quantitative intersectionality research. Sex Roles, 59, 312-325.

Bryant-Davis, T., \& Ocamo, C. (2005). Racist incidentbased trauma. Counseling Psychologist, 33,479-512.

Bui, K., \& Takeuchi, (1992). Ethnic minority adolescents and the use of community mental health care services. American
Journal of Community Psychology 20:403417.

CACUSS (Canadian Association of College \& University Student Services) and Canadian Mental Health Association (2013). Post-Secondary Student Mental Health: Guide to a Systemic Approach. Vancouver, BC.

Canadian Mental Health Commission (2017-18). Mental Health Commission of Canada, it gives us great pleasure to place before you Changing Directions, Changing Lives: The Mental Health Strategy for Canada.

Canadian Mental Health Commission (2016). Making the Case for Investing in

Mental Health in Canada.

Cape, P. (2005). Questionnaire length, fatigue effects and response quality reviewed. Survey Sampling International.

Carpenter-Song, E. (2010). Ethno-cultural variations in the experience and meaning of mental illness and treatment: implications for access and utilization. Transcultural Psychiatry, 47(2): 224-51.

Cash, T. F., Begley, P. J., McCown, D. A., \& Weise, B. C. (1975). When counselors are heard but not seen: Initial impact of physical attractiveness. Journal of Counseling Psychology, 22(4), 273-279.

Cepeda-Benito, A., \& Short, P. (1998). Selfconcealment, avoidance of psychological services, and perceived likelihood of seeking professional help. Journal of Counselling Psychology, 45, 58-64.

Chan, K.B. (2013). International handbook of Chinese families. New York: Springer.

Chan, R. K. H., \& Hayashi, K. (2010). Gender roles and help-seeking behaviour: Promoting professional help among Japanese men. Journal of Social Work, 10(3), 243-262.

Cha, M. et al. (2008). Predictors of Intention to Practice Safer Sex among Korean College Students. Archives of Sexual behavior, 37(4):641-651.

Chang, C., Wu, T. H., Chen, C.-Y., Wang, J. D., \& Lin, C. Y. (2014). Psychometric evaluation of the Internalized Stigma of Mental Illness scale for patients with mental illnesses: Measurement invariance across time. PLoS ONE, 9(6), e98767.

Chiu, M. Y. L., Yang, X., Wong, H. T., \& Li, J. H. (2015). The mediating effect of affective stigma between face concern and general mental 
health - The case of Chinese caregivers of children with intellectual disability. Research in Developmental Disabilities, 36, 437-446.

Chong, S. A., Verma, S., Vaingankar, J. A., Chan, Y. H., Wong, L. Y., \& Heng, B. H. (2007). Perception of the public towards the mentally ill in a developed Asian country. Social Psychiatry and Psychiatric Epidemiology, 42(9), 734 739.

Chowdhury, A. N., Sanyal, D., Bhattacharya, A., Dutta, S. K., De, R., Banerjee, S. Weiss, M. G. (2001). Prominence of symptoms and level of stigma among depressed patients in Calcutta. Journal of the Indian Medical Association, 99(1), 20-23.

Cho, Y., \& Haslam, N. (2010). Suicidal ideation and distress among immigrant adolescents: The role of acculturation, life stress, and social support. Journal of Youth and Adolescence, 39, 370-379.

Cole, E. (2009) Intersectionality and research in psychology. American Psychologist, 64(3), 170-180.

Corrigan, P. (2004). How stigma interferes with mental health care. American Psychologist, 59, 614-624.

Corrigan, P. W., \& Wassel, A. (2008). Understanding and influencing the stigma of mental illness. Journal of Psychosocial Nursing and Mental Health Services, 46, 42-48.

Corrigan, P. W., Watson, A. C., Warpinski, A. C., \& Gracia, G. (2004). Stigmatizing attitudes about mental illness and allocation of resources to mental health services. Community Mental Health Journal, 40, 297307.

Corrigan, P. W., Watson, A. C., \& Barr, L. (2006). The self-stigma of mental illness: Implications for self-esteem and self-efficacy. Journal of Social and Clinical Psychology, 25, 875-884.

Courtenay, W. H. (2000a). Engendering health: A social constructionist examination of men's health beliefs and behaviours. Psychology of Men and Masculinity, 1, 4-15.

Courtenay, W. H. (2000b). Constructions of masculinity and their influence on men's well-being: a theory of gender and health. Social Science and Medicine, 50(10), 13851401.

Costello E. J, Foley, D. L., Angold, A., (2006). 10-year research update review: the epidemiology of child and adolescent psychiatric disorders: II. Developmental epidemiology. Journal of American Academy of Child and Adolescent Psychiatry; 45, 8-25.

Crenshaw, K. (1989a). Demarginalizing the intersection of race and sex: Black feminist critique of antidiscrimination doctrine, feminist theory and antiracist politics. University of Chicago Legal Forum, 1989(8), 139-67.

Crenshaw, K. (1991b). Mapping the margins: intersectionality, identity politics, and violence against women of color. Stanford Law Review, 43, 1241-1299.

Crenshaw, K. (2017c). On Intersectionality: Essential Writings. New Press. New York, NY.

Danermark, et al., (2002). Explaining Society, Critical Realism in the Social Sciences, Critical Realism Interventions. Routledge, London.

Davis, A. (1981). Women, race and class. New York: Random House.

Davies, J., McCrae, B.P., Dochnahl, A., Pickering, T., Harrison, Zakrzewski, \& Wilson (2000) Identifying male college students' perceived health needs, barriers to seeking help, and recommendations to help men adopt healthier lifestyles. Journal of American College Health, 48, 259-267.

Das, A.K. Kemp, S. F. (1997). Between two worlds: Counseling South Asian Americans. Journal of Multicultural Counseling and Development, 10, 2-15.

Deane, F. P., Wilson, C. J., \& Ciarrochi, J. (2001). Suicidal ideation and help-negation: Not just hopelessness or prior help. Journal of Clinical Psychology, 57, 1-14.

De Maio, F. G., \& Kemp E. (2010). The deterioration of health status among immigrants to Canada. Global Public Health, 5(5), 462-478.

Dodson, T. A., \& Borders, L.A.D. (2006). Men in traditional and non-traditional careers: Gender role attitudes, gender role conflict, and job satisfaction. The Career Development Quarterly, 54, 283-296.

Donadey, A. (2002). Negotiating Tensions: Teaching about Race Issues in Graduate Feminist Classrooms. NWSA Journal, 14(1), 82-102.

Dyson, R., \& Renk, K. (2006). Freshman adaptation to university life: depressive symptoms, stress, and coping. Journal of Clinical Psychology, 62, 1231-1244. 
Eagly, A. (1987). Sex differences in social behaviour: A social role interpretation. Hillsdale, NJ: Erlbaum.

Eisenberg, D., Downs, M. F., Golberstein, E., \& Zivin, K. (2009). Stigma and help seeking for mental health among college students. Medical Care Research and Review, 66, 522-541.

Eisenberg, D., Gollust, S.E., Golberstein, S.E., \& Hefner, J.L. (2007). Prevalence and correlates of depression, anxiety, and suicidality among university students. American Journal of Orthopsychiatry, 77, 534-542.

Eisenberg, D., Marilyn, F.D., Ezra, G, \& Zivin, K. (2009). Stigma and help seeking for mental health among college students. Medical Care Research and Review, 66, 522-541.

Else-Quest, N. M., Shibley Hyde, J. (2017). Intersectionality in quantitative psychological research. Psychology of Women Quarterly, 40(3), 319-336.

Field, A. (2009). Discovering Statistics Using SPSS (3rd Edition). London: SAGE Publication.

Fischer, A. R., \& Shaw, C. M. (1999). African Americans' mental health and perceptions of racist discrimination: The moderating effects of racial socialization experiences and selfesteem. Journal of Counseling Psychology, 46, 395-407.

Flatt, A, K. (2013). A suffering generation: six factors contributing to the mental health crisis in North American higher education. The College Quarterly, Seneca College of Applied Arts and Technology, 6.

Gary, F. A., Yarandi, H. N., \& Scruggs, F. C. (2003). Suicide among African Americans: Reflections and a call to action. Issues in Mental Health Nursing, 24, 353-375.

Gary, F. A. (2005). Stigma: Barrier to mental health care among ethnic minorities. Issues in Mental Health Nursing, 26, 979-999.

Gee, G. C., Ro, A., Shariff-Marco, S., \& Chae, D. (2009). Racial discrimination and health among Asian Americans: Evidence, assessment, and directions for future research. Epidemiological Reviews, 31, 130-151.

Giamos, C. et al. (2017). Understanding campus culture and student coping strategies for mental health. Issues in five Canadian colleges and universities. Canadian Journal of Higher Education. Volume 47(3), pp 120135.

Glenn, E. N. (2015). Settler Colonialism as Structure: A Framework for Comparative Studies of U.S. Race and Gender Formation. Sociology of Race and Ethnicity. 1(1) 54-74.

Goffman, E. (1963). Stigma: Notes on the Management of Spoiled Identity. Prentice Hall.

Good, G.E., \& Wood, P.K. (1995). Male gender role conflict, depression, and help seeking: Do college men face double jeopardy? Journal of Counseling \& Development, 74, 70-75.

Gollust, S.E., Eisenberg, D., \& Golberstein, E. (2008). Prevalence and correlates of self-injury among university students. Journal of American College Health, 56, 491-498.

Gong, F., Gage, S.L., \& Tacata, L.A. (2003). Help seeking behaviour among Filipino Americans: a cultural analysis of face and language. Journal of Community Psychology 31: 469-488.

Gonzalez, J.M., Alegria, M., \& Prihoda, T.J. (2005). How do attitudes toward mental health treatment vary by age, gender, and ethnicity in young adults? Journal of Community Psychology, 33, 611-629.

Gorman, R. (2013). Mad nation? Thinking through race, class, and identity politics.

In R. Menzies, G. Reaume, \& B. LeFrançois (Eds.), Mad matters: A critical reader in Canadian Mad studies. Toronto: Canadian Scholars Press.

Government of Canada (2017). The human face of mental health and mental illness in Canada. Ottawa: Minister of Public Works and Government Services of Canada.

Government of Ontario (2011). Open Minds Healthy Minds Ontario's Comprehensive Mental Health and Addictions Strategy.

Grace, S. L., et al. (2016). The mental health status of ethnocultural minorities in Ontario and their mental health care. BMC Psychiatry. 16:47.

Griffiths, K. M., Christensen, H., Jorm, A. F., Evans, K., \& Groves, C. (2004). Effect of web-based depression literacy and cognitive behavioural therapy interventions on stigmatizing attitudes to depression: Randomized controlled trial. British Journal of Psychiatry, 185, 342-342-349. 
Griselda, V. (2009). The mediating effect of acculturation on the effectiveness of culturally adapted cognitive behavioural therapy with Mexican Americans suffering from depression. The University of Texas at Austin.

Hansson, E., Tuck, A., Lurie, S. (2012). Rates of mental illness and suicidality in

immigrant, refugee, ethnocultural and racialized groups in Canada. Canadian Journal of Psychiatry. 57:111-21.

Han, M., \& Pong, H. (2015). Mental health helpseeking behaviours among Asian American community college students: The effect of stigma, cultural barriers, and acculturation. Journal of College Student Development, 56(1), 1-14. doi:10.1353/csd.2015.0001.

Harper, D., \& Thompson, A.R. (2012). Qualitative research methods in mental health and psychotherapy. New York, NY: John Wiley.

Hicks, T., \& Heastie, S. (2008). High school to college transition: a profile of the stressors, physical and psychological health issues that affect the first-year on-campus college student. Journal of Cultural Diversity, 15, 143-147.

Hill Collins, P., \& Bilge, S. (2016). Intersectionality. Cambridge: Polity Press.

Howarth, C. (2006). Race as stigma: Positioning the stigmatized as agents, not objects. Journal of Community \& Applied Social Psychology, 16, 442-451.

Hun-Bin Shue et al (2017) An Exploratory Study of Help-Seeking Attitudes and Coping Strategies Among College Students by Race and Gender. Measurement and Evaluation in Counselling and Development, 37, 3.

Hsu, L. (2011). Asian students changing the face of Canadian universities. Retrieved fromhttp://www.wantchinatimes.com/new s-subclass.

Hwang, W. \& Ting, J. Y. (2008). Disaggregating the effects of acculturation and acculturative stress on the mental health of Asian Americans. Cultural Diversity and Racialized Psychology, 14, 147-154.

Hyman, I., \& Jackson, B. (2010). The healthy immigrant effect: A temporary phenomenon? Health Policy Research Bulletin, 17, 17-21.

Hysenbegasi, A., Hass, S.L., \& Rowland, C.R. (2005). The impact of depression on the academic productivity of university students. Journal of Mental Health Policy and Economics, 8, 145-151.

Javier, J.R., Lahlff, M., Ferrer, R.R., \& Huffman, L.C. (2010). Examining depressive symptoms and use of counseling in the expat year among Filipino and non-Hispanic white adolescents in California. Journal of Development and Behavioural Pediatrics, 31, 295-303.

John, D.A., de Castro, A.B., Martin, D.B., Duran, B., \& Takeuchi, D.T. (2012). Does an immigrant health paradox exist among Asian Americans? Associations of nativity and occupational class with self-rated health and mental disorders. Social Science Medicine, 75, 2058-2098.

Jones C. P., LaVeist TA, Lillie-Blanton M. (2000). "Race" in the epidemiologic literature: an examination of the American Journal of Epidemiology, 1921-1990.

Jorm, A.F., Korten, A.E., Jacomb, P.A., Christensen, H., Rodgers, B., \& Pollitt, P.

(1997). Mental health literacy: A survey of the public's ability to recognize mental disorders and their beliefs about the effectiveness of treatment, Medical Journal of Australia, 166(4), 182-186.

Khanlou, N. (2003a). Mental health promotional education in multicultural settings.

Nurse Education, 2, 96-103.

Khanlou N, Koh J, \& Mill C. (2008). Cultural identity and experiences of prejudice

and discrimination of Afghan and Iranian immigrant youth. International Journal of Mental Health \& Addiction, 6(3), 494-513.

Khanlou, N. (2010b). Migrant mental health in Canada. Canadian Issues, Summer, pp. 9-16.

Knifton, L. (2012). Understanding and addressing the stigma of mental illness with racialized communities. Journal Health Sociology Review, 21, 3.

Kisch, J., Leino, E.V., \& Silverman, M.M. (2005). Aspects of suicidal behaviour, depression, and treatment in college students. National College Health Assessment Survey, 35, 3-13.

Komiya, N., Good, G. E., \& Sherrod, N. B. (2000). Emotional openness as a predictor of college students' attitudes toward seeking psychological help. Journal of Counseling Psychology, 47, 138-143.

Kühberger, A., Fritz, A., Lermer, E., \& Scherndl, T. (2015). The significance fallacy in inferential statistics. BMC Research Notes, 8, 84. 
Kwok, J. (2013). Factors that influence the diagnoses of Asian Americans in mental health: An exploration. Perspectives in Psychiatric Care, 49(4), 288-292.

Islam, F. (2013). Examining the healthy immigrant effect for mental health in Canada. University of Toronto Medical Journal, 90(4), 1-7.

Iwamoto, D., Liu, W. M., \& McCoy, T. E. (2011). An exploratory model of substance use among Asian American women: The role of depression, coping, peer use and Asian values. Journal of Ethnicity in Substance Abuse, 10(4), 295-315.

Leong, F. T. L., Kim, H. H. W., \& Gupta, A. (2011). Attitudes toward professional counseling among Asian-American college students: Acculturation, conceptions of mental illness, and loss of face. Asian American Journal of Psychology, 140, 140-153.

Leong, F., Park, Y.S., \& Kalibatseva, Z. (2013). Disentangling immigrant status in mental health: psychological protective and risk factors among Latino and Asian American immigrants. American Journal of Orthopsychiatry, 84, 361-371.

LeVasseur, M. T., Kelvin, E. A., \& Grosskopf, N. A. (2013). Intersecting identities and the association between bullying and suicide attempt among New York city youths: Results from the 2009 New York city youth risk behaviour survey. American Journal of Public Health, 103(6), 1082-1089.

Link, B. G., Struening, E. L., Neese-Todd, S., Asmussen, S., \& Phelan, J. C. (2001). Stigma as a barrier to recovery: The consequences of stigma for the self-esteem of people with mental illnesses. Psychiatric Services, 52, 16211626.

Lien, Y., Kao, Y., Liu, Y., Chang, H., Tzeng, N., Lu, C., \& Loh, C. (2015b). Internalized stigma and stigma resistance among patients with mental illness in Han Chinese population. Psychiatry Quarterly, 86(2).

Lipson, J.G., \& Meleis, A.I. (1983). Issues in health care of Middle Eastern patients. Cross-Cultural Medicine, 139, 854-861.

Livingston, J., Patel, N., Bryson, S., Hoong, P., Lal, R., Morrow, M. (2018) Stigma Associated with Mental Illness Among Asian Men in Vancouver, Canada. International Journal of Social Psychiatry.
Lou, Y. \& Beaujot, R. (2005). What happens to the healthy immigrant effect: The mental health of immigrants to Canada? Discussion paper No. 05-15. London, ON: Population Studies Centre, University of Western Ontario.

Loya, F., Reddy, R., \& Hinshaw, S. P. (2010). Mental illness stigma as a mediator of differences in Caucasian and South Asian college students' attitudes toward psychological counseling. Journal of Counseling Psychology, 57, 484484.

Mackenzie, S., Wiegel, J.R., Mundt, M., Brown, D., Saewyc, E., Heilegenstein E., Harahan, B., \& Fleming, M. (2011). Depression and suicide ideation among students accessing campus healthcare. American Journal of Orthopsychiatry, 81, 101-107.

MacKean, G. (2011). Mental Health and Well-being in Postsecondary Education Settings: A Literature and Environmental Scan to Support Planning and Action in Canada. A Report for the June 2011 Pre-CACUSS Workshop.

McGough et al, (2018). Experience of providing cultural safety in mental health to Aboriginal patients: A grounded theory study. International Journal of Mental Health Nursing, 27(1):204-213.

Mental Health Commission of Canada. (2012). Changing Directions, Changing Lives: The Mental Health Strategy for Canada. Calgary, $A B$.

Mikolajczyk, R.T., Bredehorst, M., Kheilalfat, N., Maler, C., \& Maxwell, A.E. (2007). Correlates of depressive symptoms among Latino and Non-Latino White adolescents: findings from the 2003 California Health Interview Survey. BMC Public Health, 21, 7-21.

Mohanty, C., Russo, A., \& Torres, L. (Eds.). (1991). Third world women and the politics of Feminism. Bloomington: Indiana University Press.

Morrow, M. \& Halinka-Malcoe, L. (2017). Critical inquiries for social justice in mental health. Toronto, ON: University of Toronto Press.

Mowbray, C.T., Mandiberg, J.M., Stein, C.H., Megivern, D., Strauss, S. et al. (2006). Campus mental health services: recommendations for change. American Journal of Orthopsychiatry, 76, 226-237.

Mikolajczyk, R.T., Bredehorst, M., Kheilalfat, N., Maler, C., \& Maxwell, A.E. (2007). Correlates 
of depressive symptoms among Latino and Non-Latino White adolescents: findings from the 2003 California Health Interview Survey. BMC Public Health, 21, 7-21.

Minkov, M. (2010). Nations with more dialectical selves exhibit lower polarization in life quality judgments and social opinions. CrossCultural Research, 43, 230-250.

Organisation for Economic Co-operation and Development countries OECD (2011).

Ojeda, V. D., \& Bergstresser, S. M. (2008). Gender, race-ethnicity, and psychosocial barriers to mental health care: An examination of perceptions and attitudes among adults reporting unmet need. Journal of Health and Social Behaviour, 49(3), 317334.

Oh, H., Park, K., Yoon, S., \& Kim, Y. (2018) Clinical utility of Beck Anxiety Inventory in clinical and nonclinical Korean samples. Frontiers of Psychiatry, 9, 666.

Olding, M. \& Yip, A. (2014). Policy Approaches to PostSecondary Student Mental Health. OCAD University \& Ryerson University Campus Mental Health Partnership Project. Toronto, ON.

Olenick, S.G. (2012). An examination of the relationship between emotional expressivity and attitudes toward and barriers to seeking psychological help. Ph.D. Dissertation. Ball State University, Muncie, Indiana.

Pahwa, P., Karunanayake, C. P., McCrosky, J., \& Thorpe, L. (2012). Longitudinal Trends in Mental Health among Ethnic Groups in Canada. Chronic Diseases and Injuries in Canada, 32, 164-176.

Paniaguan, F., et al. (2013). The handbook of multicultural mental health: Assessment and treatment of diverse populations (2nd Ed.). San Diego, CA: Academic Press.

Parent, M.C., Hammer, J. H., Bradstreet, T. C., Schwartz, E. N., \& Jobe, T., (2018). Men's Mental Health Help-Seeking Behaviours: An Intersectional Analysis. American Journal of Men's Health, 112(1) 64-73.

Pasupuleti, R. (2013). Cultural factors, stigma, stress, and help-seeking attitudes among college students. Ph.D. Dissertation. University of Rhode Island.

Patterson, P., \& Kline, T. (2008). Report on PostSecondary Institutions as Healthy Settings.

The Pivotal Role of Student Services, Health and Learning Knowledge Centre. Victoria, B.C., Canada. (ACCC).

Paradies, Y., Ben, J., Denson, N., Elias, A., Priest, N., Pieterse, A., Gupta, A., Kelaher, M., \& Gee, G. (2015). Racism as a determinant of health: A systematic review and meta-analysis. PLOS ONE, 10(9).

Pernice, R. Brook, J. (1996). Refugee's and immigrants; mental health: Association of demographic and post-immigration factors. The Journal of Social Psychology, 136(4), 511-519.

Phillips, L. T., \& Lowery, B. S. (2018). Herd invisibility: The psychology of racial privilege. Current Directions in Psychological Science, 27(3), 156-162.

Plaut, V. C., Thomas, K. M., Hurd, K., \& Romano, C. A. (2018). Do color blindness and multiculturalism remedy or foster discrimination and racism? Current Directions in Psychological Science, 0963721418766068.

Potochnick, S., \& Perreira, K.M. (2010). Depression and anxiety among first-generation Latino youth: key correlates and implications for future research. Journal of Nervous and mental Disorders, 198, 470-477.

Prakash, B.B. et al, (2013). Religion and mental health. Indian J. Psychiatry, 55, S187-S194.

Price, E. L., McLeod, P. J., Gleich, S. S., \& Hand, D. (2006). One-year prevalence rates of major depressive disorder in first-year university students. Canadian Journal of Counselling, $40,68-81$.

Proudfoot, J. (2013). The future is in our hands: The role of mobile phones in the prevention and management of mental disorders, Australian \& New Zealand Journal of Psychiatry, 47(2), 111-113.

Prat-Sala, M. \& Redford, P. 2010. The interplay between motivation, self-efficacy, and approaches to studying. British Journal of Educational Psychology, 80, 283-305.

Rao, D., Feinglass, J., \& Corrigan, P. (2007). Racial and ethnic disparities in mental illness stigma. Journal of Nervous and Mental Disease, 195(12), 1020-1023.

Rickwood, D., Deane F.P., Wilson, C.J., \& Ciarrochi, J. (2005). Young people's helpseeking for mental health problems, Advances in Mental Health, 4(3), 218-25. 
Rickwood, D., Deane, F., \& Wilson C. (2007). When and how do young people seek professional help for mental health problems? Medical Journal of Australia 187(7), 35-39.

Richeson, J. A. (2018). The Psychology of Racism: An Introduction to the

Special Issue. Current Directions in Psychological Science, (27)3. CA: Wadsworth.

Rider, J. (2013). York University approves mental health strategy for students,

faculty and staff. Toronto, Canada. York University.

Ritsher, J. B., Otilingam, P. G., \& Grajales, M. (2003). Internalized Stigma of Mental Illness: Psychometric properties of a new measure. Psychiatry Research, 121(1), 31-49.

Rossiter, K. R. \& Morrow, M. (2011). Intersectionality framework in mental health: Moving from theory to practice. In Hankivsky, O. (ED.). Health inequalities in Canada: Intersectional frameworks and practice (pp. 312-330). Vancouver, BC UBC Press.

Ryan, A. M., \& Pintrich, P. R. (1997). Should I ask for help? The role of motivation and attitudes in adolescents' help seeking in math class. Journal of Educational Psychology, 89(2), 329-341.

Rubin, M., Watt, S. E., \& Ramelli, M. (2012). Immigrants' social integration as a function of approach-avoidance orientation and problem-solving style. International Journal of Intercultural Relations, 36, 498-505.

Ryder, A., Alden, L., \& Paulhus, D. (2000). Is acculturation unidimensional or bidimensional? A head-to-head comparison in the prediction of personality, self-identity, and adjustment. Journal of Personality \& Social Psychology, 79, 49-65.

Santor, D., Short, K., \& Ferguson, B. (2009). Taking Mental Health to School: A

Policy- Oriented Paper on School-based Mental Health for Ontario.

Sashidharan, T., Pawlow, L. A., \& Pettibone, J. C. (2012). An examination of racial bias in the Beck Depression Inventory-II. Cultural Diversity and Racialized Psychology, 18(2), 203-209.

Sam, D.L, \& Berry, J. W. (2010). Acculturation: when individuals and groups of different cultural backgrounds meet. Perspectives on Psychological Science 5, 472-484.

Sawatzky, R., Ratner, P.A., Richardson, C.G., Washburn, C., Sudmant, W., \& Mirwaldt, P. (2012). Stress and depression in students: The mediating role of stress-management self-efficacy. Nursing Research, 61(1), 13-21.

Scott, N. A., \& Siltanen, J. (2017). Intersectionality and quantitative methods: assessing regression from a feminist perspective. International Journal of Social Research Methodology, 20(4).

Smith, P.B. (2004). Acquiescent response bias as an aspect of cultural communication style. Journal of Cross-Cultural Psychology, 35, 5061.

Statistics Canada (2017), Population by Visible Minority Groups and Median Age, Canada, 2001 and 2016". Focus on Geography Series, 2016.

Strine, T.W., Mokdad, A.H., \& Dube, S.R. (2008). The association of depression and anxiety with obesity and unhealthy behaviours among community-dwelling U.S. adults. General Hospital Psychiatry, 30, 127-137.

Storrie, K., Ahern, K., \& Tuckett, A. (2010). A Systematic Review: Students with Mental Health Problems-A Growing Problem. International Journal of Nursing Practice, 16(1),1-6.

Surgenor, L.J. (1985). Attitudes towards seeking professional psychological help. New Zealand. Journal of Psychology, 14, 27-33.

Tam, L. (2013). Whither indigenizing the Mad movement? Theorizing the social relations of race and madness through conviviality. In $\mathrm{R}$. Menzies, G. Reaume, \& B. LeFrançois (Eds.), Mad matters: A critical reader in Canadian Mad studies (pp. 281297). Toronto: Canadian Scholars Press.

Telzer, E.H. (2010). Expanding the acculturation gapdistress model: an integrative review. Human Development, 53, 313-340.

Ting, J. Y., \& Hwang, W. (2009). Cultural influences on help-seeking attitudes in Asian American students. American Journal of Orthopsychiatry, 79(1), 125-132.

Vogel, D. L., Heimerdinger-Edwards, S. R., Hammer, J. H., \& Hubbard, A. (2011). "Boys don't cry": Examination of the links between masculine norms and help-seeking attitudes for men 
from diverse cultural backgrounds. Journal of Counseling Psychology, 58, 368-382.

Vogel, D. L., Wade, N. G., \& Hackler, A. H. (2007). Perceived public stigma and the willingness to seek counseling: The mediating roles of self-stigma and attitudes toward counseling. Journal of Counseling Psychology, 54, 40-50.

Walsemann, K. M. et al., (2011). The Intersection of School: Racial Composition on Adolescent Depression \& Somatic Symptoms. Social Science Medicine Vol 72(11).

Weiss, M., Jadhav, S., Raguram, R., Vounatsou, P., \& Littlewood, R. (2001). Psychiatric stigma across cultures: Local validation in Bangalore and London. Anthropology \& Medicine, 8(1), 71-87.

World Mental Health International College Student Project (2018).

World Health Organization, (2010). Health and Human Rights. Retrieved from: http://www.who.int/mediacentre/factsheet s/fs323/en/.

Wright, A., Jorm, A.F., Harris, M.G., McGorry, P.D. (2007). What's in a name?

Is accurate recognition and labelling of mental disorders by young people associated with better help-seeking and treatment preferences? Society for Psychiatry and Epidemiology,42(3), 244-250.

Wu, Z., \& Schimmele, C. (2005). The healthy migrant effect on depression: Variation over time? Canadian Studies in Population, 32(2), 271295.

Xu, M.A., \& McDonald, J.T. (2010). The mental health of immigrants and minorities in Canada: The social and economic effects. Canadian Issues, Summer 2010, 29-32.

Yamawaki, N., Pulsipher, C., Moses, J. D., Rasmuse, K. R., \& Ringger, K. A. (2011). Predictors of negative attitudes toward mental health services: A general population study in Japan. European Journal of Psychiatry, 25(2), 101-110.

Yang, L. H. (2007). Application of mental illness stigma theory to Chinese societies: Synthesis and new directions. Singapore Medical Journal, 48(11), 977-985.

Yang, L. H., \& Kleinman, A. (2008). Face and the embodiment of stigma in China: The cases of schizophrenia and AIDS. Social Science \& Medicine, 67(3), 398-408. doi: 10.1016/j.socscimed.2008.03.011.
Yang, L. H., Thornicroft, G., Alvarado, R., Vega, E., \& Link, B. G. (2014). Recent advances in crosscultural measurement in psychiatric epidemiology: Utilizing 'what matters most' to identify culture-specific aspects of stigma. International Journal of Epidemiology, 43(2).

Young, D. K., \& Ng, P. Y. (2016). The prevalence and predictors of self-stigma of individuals with mental health illness in two Chinese cities. International Journal of Social Psychiatry, 62(2), 176-185. 
Table 1: List of Survey Instruments

\begin{tabular}{|c|c|c|}
\hline Variables & Instrument & Items \\
\hline Socio-demographic Factors & Questionnaire designed by the researcher. & 25 \\
\hline Attitudes & $\begin{array}{l}\text { Attitudes Toward Seeking Professional Help } \\
\text { Scale (Fischer \& Farina, 1995). }\end{array}$ & 10 \\
\hline $\begin{array}{l}\text { Intention } \\
\text { Stigma } \\
\text { Expertness of Professionals }\end{array}$ & $\begin{array}{l}\text { Beliefs About Psychological Services Scale } \\
\text { (Aegisdottir, \& Gerstein, 2009). }\end{array}$ & 18 \\
\hline $\begin{array}{l}\text { Identification with Mainstream Culture } \\
\text { Identification with Heritage Culture }\end{array}$ & $\begin{array}{l}\text { Vancouver Index of Acculturation (Ryder, Alden } \\
\text { \& Paulhus, 2000). }\end{array}$ & 20 \\
\hline Race-related Stress & $\begin{array}{l}\text { Race-Related Events Scale (Waelde, } \\
\text { Pennington, Mahan, Kabour, and Marquett, } \\
\text { 2010). }\end{array}$ & 22 \\
\hline Depression Symptoms & $\begin{array}{l}\text { Centre for Epidemiological Studies Depression } \\
\text { Scale (Radloff, 1977). }\end{array}$ & 20 \\
\hline Personal Help-Seeking Behaviour & $\begin{array}{l}\text { General Help-Seeking Questionnaire (Wilson, } \\
\text { Deane, Ciarrochi \& Rickwood, 2005). }\end{array}$ & 12 \\
\hline Anxiety & $\begin{array}{l}\text { Beck Anxiety Inventory (Beck, Epstein, Brown, } \\
\text { \& Steer,1988) }\end{array}$ & 21 \\
\hline
\end{tabular}


Figure 1. Sample racial/ethnic diversity $(n=491)$

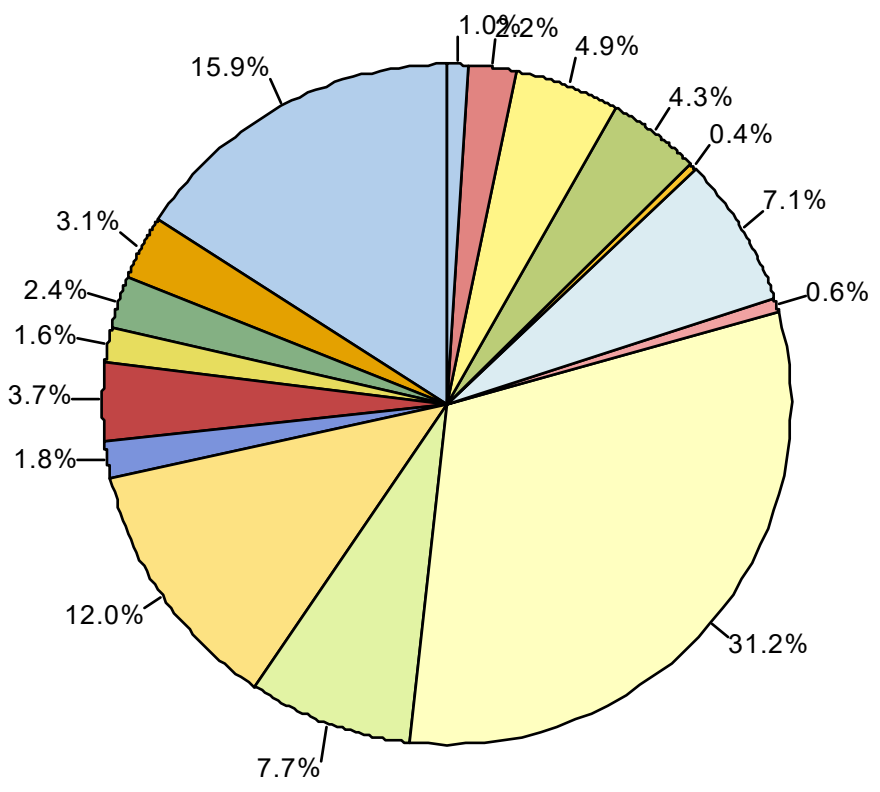

Category

Asian

Asian/Afghan

Asian/Eastern

Asian/Filipino

Asian/Indo-Caribbean

Asian/Middle Eastern

Asian/South Eastern

Asian/Southern

Black

Black/African

Black/African American

Black/Caribbean

Black/East African

Hispanic

Mixed

White/Caucasian 
Table 2: Comparison of the Mean Scores of Non-Racialized vs Racialized Students

\begin{tabular}{|c|c|c|c|c|c|c|}
\hline \multirow[t]{3}{*}{ Variable } & \multicolumn{6}{|c|}{ Racial/Ethnic Group } \\
\hline & \multicolumn{3}{|c|}{$\begin{array}{l}\text { Non-Racialized } \\
\quad(N=78)\end{array}$} & \multicolumn{3}{|c|}{$\begin{array}{r}\text { Racialized } \\
(\mathrm{N}=413)\end{array}$} \\
\hline & M & $\begin{array}{l}\text { Lower } \\
95 \% \mathrm{Cl}\end{array}$ & $\begin{array}{l}\text { Upper } \\
95 \% \mathrm{Cl}\end{array}$ & M & $\begin{array}{l}\text { Lower } \\
95 \% \mathrm{Cl}\end{array}$ & $\begin{array}{l}\text { Upper } \\
95 \% \mathrm{Cl}\end{array}$ \\
\hline Attitudes Toward Seeking Help & $28.56^{*}$ & 27.29 & 29.84 & $26.63^{*}$ & 26.16 & 27.10 \\
\hline Informal Help Seeking & 34.60 & 32.30 & 36.90 & 35.85 & 34.87 & 36.82 \\
\hline Intention to Seek Help & 4.09 & 3.84 & 4.35 & 3.70 & 3.60 & 3.81 \\
\hline Stigma & 2.56 & 2.40 & 2.73 & 2.80 & 2.71 & 2.87 \\
\hline Expertness of Professionals & 4.44 & 4.23 & 4.66 & 4.32 & 4.22 & 4.42 \\
\hline Identification with Heritage Culture & 6.18 & 5.85 & 6.50 & 6.60 & 6.43 & 6.76 \\
\hline Identification with Mainstream Culture & 6.69 & 6.42 & 6.97 & 6.36 & 6.23 & 6.49 \\
\hline Race Related Stress & $2.61^{*}$ & 1.83 & 3.40 & $5.95^{*}$ & 5.53 & 6.38 \\
\hline Anxiety Symptoms & 13.39 & 10.87 & 15.91 & 14.47 & 13.26 & 15.68 \\
\hline Depression Symptoms & 19.07 & 16.22 & 21.93 & 21.42 & 20.32 & 22.52 \\
\hline
\end{tabular}

Note: * 95\% Cl do not overlap, reflecting significant differences between the mean scores 